\title{
EXTREMELY PROFOUND HYPOTHERMIA WITHOUT BLOOD \\ BY MEANS OF EXCHANGE PERFUSION OF THE BLOOD SUBSTITUTE
}

\author{
(PRELIMINARY REPORT)
}

\author{
TATSUYUKI KUDO \\ Department of Surgery, Devision of Neurosurgery, Keio University, \\ School of Medicine, Tokyo, Japan
}

(Received for publication February 4, 1963)

Surgeons dream of working in a perfectly dry operative field, whenever they struggle against the wide spread malignant tumors or huge vascular lesions combating with a massive hemorrhage. Hypothermia has offered the step to realize a safe circulatory arrest. Although in the moderate hypothermic condition a very limited time of cerebral circulatory interruption was allowed, in the profound hypothermic state, which has been developed by Gollan (9) and Juvenille(13) by means of blood stream cooling, nearly one hour of total circulatory arrest was achieved safely. In this state, by the application of the extracorporeal circulatory machine, a body temperature of around $15-20^{\circ} \mathrm{C}$ was attained. As the metabolic level falls in proportion to the body temperature, the lower the body temperature the longer will be the time permitted to stop circulation. In this view, many efforts have been made to obtain a body temperatures lower than $10^{\circ} \mathrm{C}$. However, the results were rather discouraging $(12,18,20)$.

Kudo(14) succeeded in cooling the brain to $6-7^{\circ} \mathrm{C}$ by irrigating cooled artificial blood substitute through cerebral vascular channel which was isolated from the systemic circulation. In this condition more than two hours of safe cerebral circulatory interruption was achieved experimentally. And in three clinical cases from 56 to 96 minutes of cerebral circulatory interruption was successfully obtained. In addition, our cardiac surgical group succeeded in a clinical case in restoring the normal heart beat after 90 minutes of hypothermic cardiac arrest below $10^{\circ} \mathrm{C}$ of myocardial temperature by means of selective coronary irrigation by the same cooled blood substitute. These successes have suggested to us the possibility to cool the whole body below $10^{\circ} \mathrm{C}$, perfusing harmless artificial blood substitute by means of an extracorporeal machine.

\footnotetext{
* Professsor of Surgery.
} 
This report is concerned with our experiments in obtaining an extremely profound hypothermia ranging from $10^{\circ}$ to $5^{\circ} \mathrm{C}$ for achievement of more than two hours of total circulatory arrest, which will enable the surgeons' dream to come true.

\section{METHOD}

ANIMALS: Thirty healthy adult mongrel dogs weighing from 9 to $12 \mathrm{~kg}$ have been used. Pentothal sodium was used for induction. After tracheotomy and endotracheal intubation, ether and oxygen maintained the appropriate level of anesthesia. The animal was laid supine on the operating table and surface cooling was applied until the body temperature went down to $30^{\circ} \mathrm{C}$. Occasionally succinylcholine chloride was used intravenously for intubation or against shivering. Thermister elements were put into the unilateral temporal lobe, the esophagus, the rectum and the muscle of right arm. Heparin was administered intravenously $3 \mathrm{mg} / \mathrm{kgBW}$.

EXTRACORPOREAL APPARATUS: The extracorporeal apparatus consists of a modified Lillehei-DeWall type oxygenator with helical reservoir powered by a Sigma Motor TM-2 type pump(Pu). A Keio type heat exchanger (HE) unit was interposed in the arterial line. This apparatus was connected to the animal by means of tubes introduced into superior and inferior venae cavae via the right atrium, left atrium of the heart(LA) and the right femoral artery as illustrated in Fig. 1.

In all cases arterial and venous pressures were monitored from catheters introduced into the femoral artery and vein. EKG and EEG (frontal, parietal and occipital) were recorded through the experiment.

COOLING: The extracorporeal circuit in Fig. 1 was filled with cooled (near $0^{\circ} \mathrm{C}$ ) PVP (polyvinyl-pyrrolidone) Ringer solution. The container (C) was filled with enough volume of the same cooled solution to lower the body temperature rapidly. After completion of cannulations, perfusate solution was started from the femoral artery, passed through the whole body and drove out the animal blood from the venae cavae. At the beginning, blood was accumulated in a reservoir $(\mathrm{BB})$ and stored to be returned again. And then, the blood diluted by the PVP Ringer solution was abandoned. When perfusing solution gained transparency - Hgb was around $0.5 \%$ Sahli at this time-this perfusion circuit was closed the cooling process through the heat exchanger was continued. When $5-6^{\circ} \mathrm{C}$ of cerebral temperature was attained, the circulation was discontinued, and at this moment keeping venous canulae open, circulating solution was removed by gravity from vascular system as much as possible. 


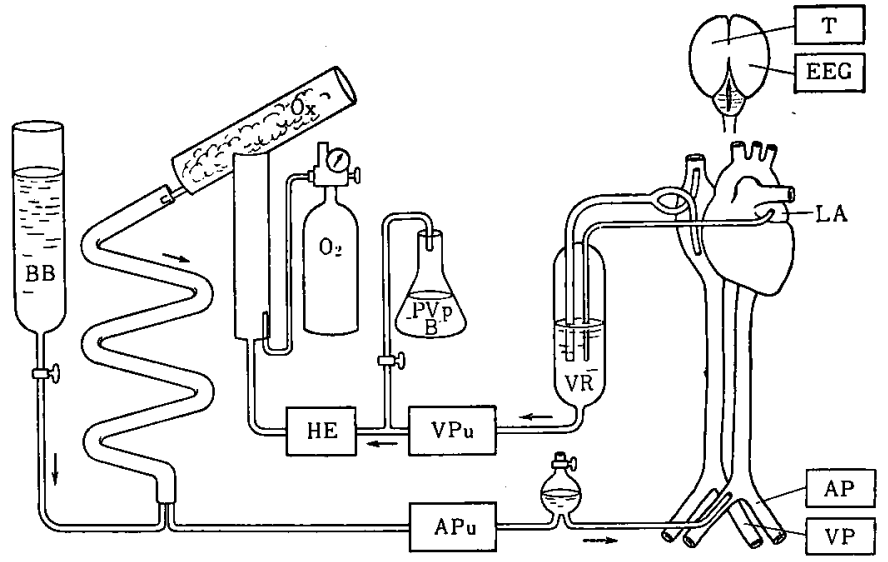

Fig. 1

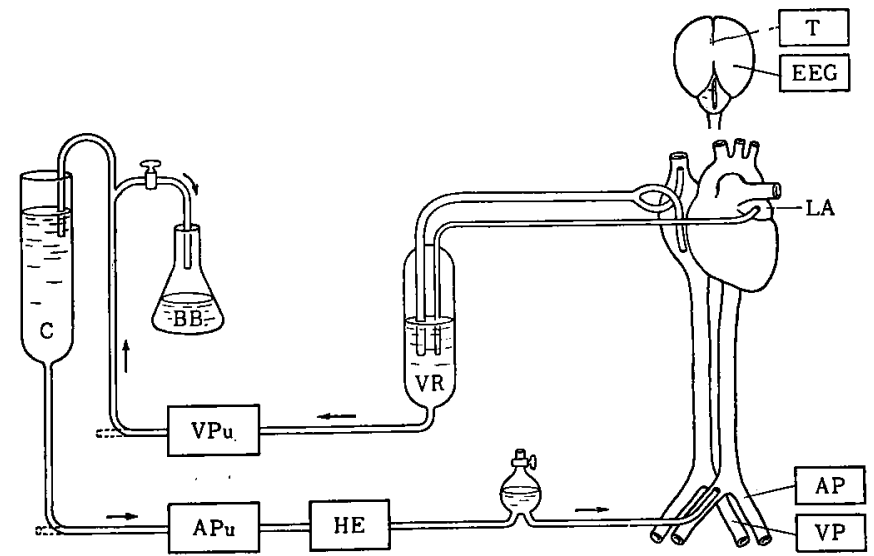

Fig. 2

AP : Arterial pressu:e

APu: Arterial pump

$\mathrm{BB}$ : Blood collecting bottle

C: Container

$\mathrm{HE}$ : Heat exchanger

LA : Left atrium
Ox: Oxygenator

PVP B: PVP collecting bottle

$T$ : Temperature

VP: Venous pressure

VPu: Venous pump

VR: Venous reservoir

REWARMING: After arbitrary interruption of the total body circulation, rewarming was started. The artificial solution, warmed passing through the heat exchanger( $\mathrm{HE}$ ), was perfused until $15^{\circ} \mathrm{C}$ of brain temperature was attained. At this time, the circuit was changed as illustrated in the Fig. 2. As the blood started to circulate, driven artificial solution was abandoned, Thus the usual 
rewarming extracorporeal circuit was completed. Blood was warmed by the heat exchanger(HE) step by step and oxygenated by the oxygenator(OX), circulating through the whole body. A warming blanket was applied to promote the rewarming process.

When about $28^{\circ} \mathrm{C}$ of esophageal temperature was attained, counter-shock was given to restore the normal heart beat in the case that the ventricular fibrillation continued and normal heart beat could not be obtained spontaneously. Before counter-shock, Isprel (Isoproterenol) was usually given through the arterial line.

PERFUSATE SOLUTION: Ringer's solution containing polyvinyl-pyrrolidone in 3.5-4 per cent concentration was used as the coolant instead of heparinized blood. The $\mathrm{pH}$ of this solution was kept at 7.0-7.2 and stored at the temperature of $2-0^{\circ} \mathrm{C}$.

BLOOD: About 800-1000 ce of the same type of heparinized blood was prepared and added at the last stage of the rewarming process to keep a normal hemoconcentration. Blood samples were collected and checked every 5 minutes before, during and after perfusion.

\section{RESULTS}

When the cooling started, rectal temperature was reduced to below $10^{\circ} \mathrm{C}$ within 5-10 minutes, and after 12-25 minutes the cerebral temperature attained the same level. During the circulatory arrest, the cerebral temperature raised $3-4^{\circ} \mathrm{C}$ on an average. This seemed to be due to the equalization of the temperatures of the body tissues. The dog lost its heart beat at $20-22^{\circ} \mathrm{C}$ and regained it at $23-27^{\circ} \mathrm{C}$ with or without ventricular fibrillation. Spontaneous respiration restarted usually between $26^{\circ}$ to $28^{\circ} \mathrm{C}$. The pupils became markedly mydriatic and lost reaction to light during cooling stage until after regaining $30^{\circ} \mathrm{C}$ of cerebral temperature.

When the normal circulation was restored and the normal body temperature was regained, all animals restored spontaneous respiration, normal size of pupils and reacted vividly to light, and moved nostrils, mouth, neck and legs. In the recovery stage the EKG of survived animals showed only a slight change of rate, amplitude of QRS, and deviation of ST-segment. Below $16-18^{\circ} \mathrm{C}$ the EEG appeared to flatten entirely, Although there were several factors influencing the EEG, for example, levels of anesthesia, arterial pressure and respiration-, the brain temperature seemed to be the greatest factor. The EEG in the rewarming stage showed no marked finding except slight paroxysmal activity occurring in rare case, During perfusion of the blood substitute Hcrt, and Hgb. were 
examined and lowest datas of which were $0.03 \%$ and $0.05 \%$ Sahli, but by perfusing $\mathrm{Hgb}$. used to increase gradually and was between 0.3 and $0.5 \%$ Sahli. By the surviving experiment, 5 animals kept alive more than 3 days recovering consciousness.

Pathological examination revealed no marked changes in various organs, such as brain, kidney, liver and heart muscles.

\section{DISCUSSION}

Bigelow et al(3) reported that oxygen consumption fell consistently with reduction in body temperature (to $18^{\circ} \mathrm{C}$ ). Lynn et al (17) observed the reduction in oxygen consumption is $27 \%$ at a rectal temperature of $30^{\circ} \mathrm{C}$, and it decreases linearly with temperature, and extrapolation to zero oxygen consumption would place the rectal temperature at $10^{\circ} \mathrm{C}$. Similar relationships were noted for the dog by Woodruff(23) and for the rat by Adolph(1) and by Fuhrman(8). An exponential decrease in oxygen consumption and carbon dioxide production with decrease in the rectal temperature were reported by Velten ${ }^{(21)}$ and Spurr et al(19), Gordon(11) determined the safe limits of circulatory arrest on the basis of oxygen consumption at hypothermic levels, which were used widely as a parameter in cardiac surgery. These datas suggest to us to secure the prolonged total circulatory arrest under near zero body temperature, provided the safe cooling and rewarming is guaranteed.

In many experimental works $(2,9)$ cooling below $10^{\circ} \mathrm{C}$ has been attained with subsequent recovery. Recently Gollan(10), using extracorporeal cooling, succeeded in reviving dogs with body temperatures as low as $0^{\circ} \mathrm{C}$ under cardiac arrest for one hour. Dubost(7) clinically attained around $10^{\circ} \mathrm{C}$ and one hour and thirty minutes of cardiac arrest with recovery. However, there are some pessimistic views about cooling below $10^{\circ} \mathrm{C}$ that may threaten brain damages and paralysis of extremities. Gordon(11) noticed that during cooling the blood viscosity increases approximately $2 \frac{1}{2}$ per cent per degree $\mathrm{C}$. of body temperature reduction. At $8^{\circ} \mathrm{C}$ it becomes $75 \%$ more viscous than at $38^{\circ} \mathrm{C}$. Lee et al(15) noticed the denaturation of plasma proteins as a cause of morbidity and death, and which results the alteration of the blood viscosity. Björk $(4,5)$ described the brain damage to children of deep hypothermia. Gordon limited the depth of hypothermia to $8^{\circ} \mathrm{C}$ and the duration of circulatory arrest to one hour from his experimental and clinical experiences. For the purpose of excluding the disadvantages of the blood, several authors ${ }^{(6,16)}$ have tried to dilute the blood by mixing plasma expander.

In reviewing the trial of complete replacement of the blood perfusate, only Woodhall(22) used Ringer's solution for the purpose of cerebral irrigation of anti- 
tumor drugs through the brain vessels at the brain temperature of $20^{\circ} \mathrm{C}$ in six dogs.

The results of our perfusion method using artificial solution might exclude the disadvantage of the blood as the coolant and provide additional datas about this problem. In this author's opinion, the artificial solution is better than blood as a coolant so far as it concerns extremely deep hypothermia.

\section{SUMMARY AND CONCLUSION}

This new method of prolonged total body circulatory interruption is devised under extremely profound hypothermia by means of the exchange perfusion of a blood substitute using extracorporeal circulatory machine.

There are several significances of this method:

1) Prolonged total body circulatory interruption is obtained.

2) Temperature near $0^{\circ} \mathrm{C}$ is obtained very rapidly.

3) An absolutely bloodless surgical field is secured under this condition.

4) No sequelae are noticed after recovery.

5) No blood is perfused during the cooling period. This procedure facilitates high flow and rapid cooling.

6) A great future is expected to perform a riskful operation radically and safely under this new method.

\section{A CLINICAL CASE}

Clinically $1 \frac{1}{2}$ hours total body circulatory arrest under this procedure had been experienced and is reported here briefly.

This new total body perfusion method was applied clinically on December 19, 1962 on a 21 years old male volunteer who was diagnosed with a malignant tumor in the lower abdomen and with wide spread infiltration (sigmoid, rectum, urinary bladder, ureter and retroperitoneal vascular system) 11/2 hours circulatory arrest was obtained and esophageal temperature reached $5.4^{\circ} \mathrm{C}$. An absolutely bloodless surgical field was obtained, being so unusual that it has been described as cadaveric. Subtotal removal of the wide spread cancer was performed very easily and safely, although total removal was impossible because of infiltration. Vessels were ligated carefully, and parenchymatous oozing was controlled by means of sponge packing. After the restoration of the blood coagulability, hemorrhage was controlled by coagulation relatively easily. The patient regained consciousness postoperatively and showed no mental or other kind of disturbances. 


\section{REFERENCES}

1. Adolph, E. F.: Oxygen consumption of hypothermic rats and acclimatisation to cold. Am. J. Physiol. 161: 359-373, 1950.

2. Andjus, R. K. and Smith, A. U.: Reanimation of adult rats from body temperature between $0^{\circ}$ and $2^{\circ} \mathrm{C}$. J. Physiol. 128: 446-472, 1955.

3. Bigelow, W. G., Lindsay, W. K., Harrison, R. C., Gordon, R. A., and Greenwood, W. F.: Oxygen transport and utilization in dogs at low temperature. Am. J. Physiol. 160: 125-137, 1950.

4. Björk, V. O.: An effective blood heat exchanger for deep hypothermia in association with extracorporeal circulation but excluding the oxygenator. J. Thorac. Cardiovasc. Surg. 40: 237-252, 1960.

5. Björk, V. O. and Hultquist, G.: Brain damage in children after deep hypothermia for open-heart surgery. Thorax. 15: 284-291, 1960.

6. Drake, C. T., Macallad, F., and Lewis, F. J.: The effect of low molecular weight dextran upon the blood flow during extracorporeal circulation. J. Thorac. Cardiovasc. Surg. 42: 735-742, 1962.

7. Dubost, Ch. and Blondean, P.: The association of the artificial heart-lung with deep hypothermia in open heart surgery. J. Cardiovasc. Surg. 1: 85-93, 1960.

8. Fuhrman, F. A. and Field, J.: Influence of temperature on the stimulation of oxygen consumption of isolated brain and kidney by 2.4 dinitrophenol. J. Pharmacol. Expr. Therap. 75: 58-63, 1942.

9. Gollan, F., Hamilton, E. C. and Meneeley, G. R.: Consecutive survival of openchest, hypothermic dogs after prolonged by-pass of heart and lungs by means of a pump-oxygenator. Surg. 35: 88-97, 1954.

10. Gollan, F.: Cardiac arrest of one hour's $0^{\circ} \mathrm{C}$ followed by survival. Fed. Proc. 13: 57, 1954.

11. Gordon, A. S.: Cerebral blood flow and temperature during deep hypothermia for cardiovascular surgery. J. Cardiovasc. Surg. 3: 299-307, 1962.

12. Jensen, J. M., Parkins, W. M. and Vars, H. M.: Possibilities and limitation of differential brain cooling in dogs. The physiology of induced hypothermia. National Acad. Science Washington, 271-278, 1956.

13. Juvenille, A. A.: Observations on hypothermia. Proc. Roy. Soc. Med. 47: 410, 1954.

14. Kudo, T.: Differential cerebral deep hypothermia by isolated cerebral vascular irrigation, preliminary report. Keio J. Med. 11: 83-85, 1962.

15. Lee, W. H. Jr., Krumhaar, D., Fonkalstrud, E. W., Schjeide, O. A., and Maloney, J. Jr.: Denaturation of plasma proteins as a cause of morbidity and death after intracardiac operations. Surg. 50: 29-39, 1961.

16. Long, D. M. J., Sanchey, L., Varco, R. L., and Lillihei, C. W.: The use of low molecular weight dextran and serum albumin as plasma expander in extracorporeal circulation. Surg. 50: 12-28, 1961.

17. Lynn, R. B., Melrose, D. G., Churchill-Davidson, H. C., and McMillan, I. K. R.: Hypothermia: Further observations in surface cooling. Am. Surg. Coll .Surg. Eng. 14: 267-275, 1954.

18. Neville, W. E., Clowes, G. H. A. Jr., Kameya, S. Oz. M., and Bloor, E.: Profound hypothermia and complete circulation interruption. Am. Arch. Surg. 82: 108$119,1961$.

19. Spurr, G. B., Hutt, B. K., and Horvash, Z. M.: Responses of dogs to hypothermia. Am. J. Physiol. 179: 139-145, 1954.

20. Stephen, C. R., Dent, S., Sealy, W. C., and Hull, K.: Anesthetic and metabolic 
factors associate with continued extracorporeal circulation and hypothermia. Am. J. Cardiol. 6: 737-751, 1960.

21. Velten, W.: Über oxydation in Warmblüter bei subnormalen Temperatur. Pflüg. Arch. ges. Physiol. 21: 361-398, 1880.

22. Woodhall, B., Hall, K., Mahaley, S. Jr., and Jackson, J.: Chemotherapy of brain cancer. Experimental and clinical studies in localized hypothermic cerebral perfusion. Ann. Surg. 150: 640-652, 1959.

23. Woodruff, L. M.: Survival of hypothermia by the dog. Anesthediology. $2: 410-420$, 1941. 